\title{
ROLE OF FINE NEEDLE ASPIRATION CYTOLOGY IN BREAST CANCER SCREENING
}

\author{
Minakeshi Rana ${ }^{1}$ Surinder Kumar Atri2 ${ }^{2}$ Shweta Bhagat ${ }^{3}$, Varinder Mohan Rana ${ }^{4}$
}

${ }^{1}$ Consultant Gynaecology and Obstetrics, DH Samba; Jammu, J\& K Health Services.

${ }_{2}^{2}$ Associate Professor, Department of Pathology, Government Medical College, Jammu, Jammu and Kashmir, India.

3Junior Resident, Department of Obstetrics and Gynaecology, Government Medical College, Jammu, Jammu and Kashmir, India.

${ }_{4}^{4}$ Medical Officer, DH Rajouri, J \& K Health Services, Jammu, Jammu and Kashmir, India.

\section{BACKGROUND}

ABSTRACT

A cross sectional study for screening of carcinoma breast was done on pregnant women attending gynaecology and surgery OPD at District Hospital Samba, Jammu. All women with sign and symptoms of breast disease who attended the Gynaecology and Surgery OPD from March 2015 to March 2017 were included in the study.

\section{MATERIALS AND METHODS}

Clinical examination was done by gynaecologist and surgeon. Fine needle aspiration was done by pathologist and was reported by consultant pathologist. Histopathology reports of these patients where available were also correlated.

\section{RESULTS}

The age of the patients ranged from 7 years to 88 years, maximum number of cases were seen in the age group of 21-30 years, followed by of 31-40 years. Clinical presentation of patients was with lump breast, diffuse swelling, nipple discharge, mastalgia, retracted nipple, axillary lymph node, skin manifestation. Fine needle aspiration diagnosis: maximum number of cases were of benign lesions (74.2\%) followed by $12.4 \%$ inflammatory cases and $10.06 \%$ cases of carcinoma. Among the benign diagnosis, Fibroadenoma (20.06\%) was the most common.

\section{CONCLUSION}

That means fine needle aspiration can fairly distinguish inflammatory, benign and malignant lesions of breast. Therefore fine needle aspiration can be used for mass screening of population for carcinoma breast.

\section{KEY WORDS}

Carcinoma, Breast, FNAC, Cytology, Screening.

HOW TO CITE THIS ARTICLE: Rana M, Atri SK, Bhagat S, et al. Role of fine needle aspiration cytology in breast cancer screening. J. Evolution Med. Dent. Sci. 2019;8(08):522-526, DOI: 10.14260/jemds/2019/115

\section{BACKGROUND}

Carcinoma of the breast is the most common non-skin malignancy in women worldwide. Breast cancer is the most common cancer in women in India and accounts for $27 \%$ of all cancers in women.1,2 According to a 2016 report $^{3}$ published by the Indian Council of Medical Research, breast cancer is now the most common cancer among urban Indian women, with approximately 1, 44, 000 new cases being reported every year. Carcinoma breast is the second leading cause of cancer mortality after lung cancer. Globally over the last several decades, the incidence of breast cancer has increased and the greatest increase has been seen in Asian countries where breast cancer incidence peaks among women in their forties whereas in the United States and Europe, it peaks among women in their sixties.4,5,6 India with its multilingual, and multiethnic society has reported breast cancer as the commonest cancer in urban Indian females, and the second commonest in the rural Indian women. ${ }^{3}$

'Financial or Other Competing Interest': None.

Submission 18-01-2019, Peer Review 10-02-2019,

Acceptance 14-02-2019, Published 25-02-2019.

Corresponding Author:

Dr. Surinder Kumar Atri,

Associate Professor,

House No. 24, Lane 51, Behind Sunny Farms,

Greater Kailash Post Office, Gangyal, Jammu,

Jammu and Kashmir, India.

E-mail: surinderkumaratri@gmail.com

DOI: $10.14260 /$ jemds/2019/115

\section{(c) $(i)(5)$}

As per the ICMR HBCR data, breast cancer is the commonest cancer among women in urban registries of Delhi, Chandigarh, Mumbai, Chennai, Guwahati, and Trivandrum where it constitutes $20-30 \%$ of all cancers in females. ${ }^{3}$ Almost all Indian women often do not present for medical care early enough due to various reasons such as illiteracy, lack of awareness, financial constraints, lack of an organized screening programmes and paucity of diagnostic aids. It is hardly surprising that the majority of breast cancer patients in India are still treated at locally advanced and metastatic stages ${ }^{7}$. Detection of it in earlier stages is made possible by a triple assessment which includes clinical examination, radiological imaging and tissue pathology. Triple assessment is a very useful diagnostic tool to evaluate patients with breast lumps and to detect patients with breast cancers with an overall accuracy of $99.3 \% .^{8}$

Breast diseases are broadly classified into Inflammatory, benign and malignant diseases. The inflammatory diseases are very rare and accounts for $1 \%$ of breast symptoms. Various inflammatory diseases are acute mastitis, periductal mastitis, duct ectasia, fat necrosis, lymphocytic mastopathy and granulomatous mastitis. These diseases present clinically as palpable mass and have to be distinguished from carcinoma breast. Benign epithelial lesions are grouped into three categories according to the subsequent risk of developing breast cancer: (1) Non-proliferative breast changes, (2) Proliferative breast disease without atypia, and (3) Proliferative breast disease with atypia. Several epidemiological studies have established the association of 
benign epithelial lesions with the later development of invasive cancer. These lesions come to clinical attention as mammographic findings or as incidental findings in surgical specimens. Non-proliferative changes do not increase the risk of cancer. Proliferative breast disease without atypia is associated with a 1.5-2 fold increased risk, while proliferative disease with atypia is associated with 4-5 fold increased risk. The large majority of breast cancers are detected during the reproductive years. The incidence curve starts rising at puberty, increases steeply up to menopausal age, and levels off afterwards. However, breast cancer can develop at any age from childhood to old age. Almost all ( $>95 \%)$ of breast malignancies are adenocarcinomas that first arise in the duct/lobular system as carcinoma in-situ; at the time of clinical detection, majority (at least 70\%) have already breached the basement membrane and invaded the stroma. As carcinoma breast is now leading cancer in females in India and there are precursor lesions that progress to invasive carcinoma. We planned this study to assess the accuracy of fine needle aspiration cytology in preoperative diagnosis of carcinoma breast.

\section{MATERIALS AND METHODS}

A cross sectional study was conducted on women attending gynaecology and Surgery OPD with sign and symptoms suspicious of disease of breast at District hospital Samba, Jammu; Jammu and Kashmir from March 2015 to March 2017. The women who presented with symptoms like lump breast, diffuse swelling breast, nipple discharge, mastalgia, retracted nipple, axillary lymph node, ulceration of skin, peau d' orange appearance of skin were included in the study. In each case personal information and clinical history like age, size of swelling, duration of swelling, location of swelling, history of any discharge from the nipple, pain, adherence to adjacent structures, detailed history, general physical examination and local examination of breast was carried out. Fine needle aspiration cytology of all these patients and their histology where available were retrieved from cytopathology and histopathology forms of department of Pathology, Medical College, Jammu. Statistical analysis was performed using SPSS 10.0 for Windows student version (SPSS Inc., 233 South Wacker Drive, 11th Floor, Chicago, IL 60606-6412). Standard variables of specificity, sensitivity and predictive value were also applied.

\section{RESULTS}

In a two-year period from March 2015 to March 2017, 132 women had FNA cytology of the breast performed. Of these 132 women, histology was available of only 39 women.

\section{Analysis of Result of FNA Cytology}

The age of the patients ranged from 7 years to 88 years with mean age of 36 year. Maximum number of cases were seen in the age group of 21-30 years i.e. 47 cases (30.6\%) followed by 41 cases $(26.5 \%)$ in the age group of $31-40$ years, 26 cases $(16.6 \%)$ in the age group of $41-50$ years and 17 cases (14.01\%) in the age group of 11-20 years. Left breast (54.1\%) was more commonly involved than right breast (44.6\%). Upper outer quadrant of breast was the most common quadrant involved followed by upper inner quadrant. Out of 132 patients, 100 cases (75.7\%) presented with breast lump while the swelling was diffuse in 5 cases (3.4\%). Nipple discharge was seen in 3 cases (2.6\%) and mastalgia in 4 cases (2.6\%). Axillary lymph node was involved in 5 cases (3.8\%), 4 cases $(2.6 \%)$ presented with retracted nipple, 3 patients $(1.9 \%)$ had peau d' orange appearance of the overlying skin while 1 patient $(0.7 \%)$ presented with ulcerated lesion. There was history of trauma in 2 cases (1.1\%). 5 patients (3.8\%) were lactating in our study.

\begin{tabular}{|c|c|c|}
\hline Clinical Features & No. of Cases & $\%$ \\
\hline Breast Lump & 100 & 75.7 \\
\hline Diffuse Swelling & 05 & 3.78 \\
\hline Nipple Discharge & 03 & 2.27 \\
\hline Mastalgia & 04 & 3.03 \\
\hline Retracted Nipple & 04 & 3.03 \\
\hline Axillary Lymph Node Involvement & 05 & 3.78 \\
\hline Ulceration & 01 & 0.75 \\
\hline Peau-d-Orange Appearance of Skin & 03 & 2.27 \\
\hline H/o Trauma & 02 & 1.5 \\
\hline Lactating & 05 & 3.78 \\
\hline
\end{tabular}

Fine needle aspiration cytology diagnosis revealed there were 18 cases $(13.63 \%)$ of Inflammatory lesions, 98 (74.24\%) cases of benign lesions and 16 cases (12.12) of carcinoma breast. Among the benign lesions maximum number of cases i.e. 46 cases $(34.84 \%)$ were reported as Fibroadenoma, 27 (20.45\%) cases as Fibroadenomatosis, and 22 cases $(16.66 \%)$ cases as fibrocystic change. Two cases (2.04\%) of Ductal papilloma and 1 case (1.082) of phyllodes tumour were also reported. Among the inflammatory lesions most commonly seen were acute mastitis and Breast abscess with 06 cases (33.33\%) each. Granulomatous mastitis was seen in 03 cases (16.66\%), chronic mastitis in 02 cases $(11.11 \%)$ and Fat necrosis in 1 case (5.55 \%). 16 cases $(12.12 \%)$ were categorised as malignant on FNAC.

\begin{tabular}{|c|c|c|}
\hline Diagnosis & No. of Cases & Percentage \\
\hline Breast Abscess & 06 & 4.5 \\
\hline Acute Mastitis & 06 & 4.5 \\
\hline Chronic Mastitis & 02 & 1.5 \\
\hline Granulomatous Mastitis & 03 & 2.27 \\
\hline Fat Necrosis & 1 & 0.75 \\
\hline Fibroadenoma & 46 & 34.84 \\
\hline Fibro-Adenomatosis & 27 & 20.45 \\
\hline Fibrocystic Disease & 22 & 16.66 \\
\hline Phyllodes Tumour & 1 & 0.75 \\
\hline Ductal Papilloma & 2 & 1.51 \\
\hline Carcinoma & 16 & 12.12 \\
\hline Total & 132 & 100 \\
\hline
\end{tabular}

$44.7 \%$ of cases with benign breast disease had duration of breast lump ranging from 1 to 6 months, 30.3\% had duration of less than 1 month as and $13.08 \%$ cases with benign breast disease had duration of breast disease more the 12 months. Most of the patients with malignant breast lesion i.e. 10 cases had duration of the breast lump ranging from 1 to 6 months, 2 cases had duration of 6 to 12 months. 2 cases (9.3\%) with malignant breast lesion had duration of breast lump less than 1 month and 2 cases (9.3\%) had duration more than 12 months. $74.6 \%$ of cases with benign breast lesion had breast lump ranging in size from $2-5 \mathrm{~cm}$, $24.05 \%$ had lump less than $2 \mathrm{~cm}$ and $1.2 \%$ had lump more 
than $5 \mathrm{~cm} .78 .1 \%$ of cases with malignant breast lesion had size of the breast lump ranging in size from $2-5 \mathrm{~cm}$.

\section{Analysis of Result of Histology}

Of 132 women who had FNA cytology of breast only 39 women went forward and had biopsy for histological diagnosis. On histological analysis among the benign lesions maximum number of cases i.e. 14 (43.58\%) were of fibrocystic change, followed by fibroadenoma, 9 cases $(23.07 \%)$ and infiltrating ductal carcinoma, 6 cases $(15.38 \%)$. Other diagnosis rendered on histology are shown in table given below-

\begin{tabular}{|c|c|c|}
\hline Diagnosis & No. of Cases & Percentage \\
\hline Abscess & 04 & 5.1 \\
\hline Granulomatous Mastitis & 01 & 2.56 \\
\hline Fibroadenoma & 09 & 23.07 \\
\hline Fibrocystic Change & 14 & 43.58 \\
\hline Adenomatoid Hyperplasia & 01 & 2.56 \\
\hline Infiltrating Ductal Carcinoma & 06 & 15.38 \\
\hline Normal Breast Tissue & 02 & 5.1 \\
\hline Inadequate Material & 03 & 7.69 \\
\hline Total & 39 & 100 \\
\hline \multicolumn{3}{|c|}{ Table 3. Table Showing Diagnosis on Histology } \\
\hline
\end{tabular}

\section{Correlation of Fine Needle Aspiration Cytology and Histology}

Out of 30 cases reported as benign breast disease on cytology, 27 cases were reported as benign on histology while 3 cases had normal breast tissue/inadequate sample on histological examination as shown in table 4. One of the cases diagnosed as fibroadenoma on cytology was reported as fibrocystic change on histology while one case reported as ductal papilloma on cytology was reported as adenomatoid hyperplasia on histology. One of the case which had unsatisfactory sample on FNAC was reported as fibrocystic change on histology while there was one case which had unsatisfactory sample on both FNAC and histology.

\begin{tabular}{|c|c|c|c|c|}
\hline \multicolumn{2}{|c|}{ FNAC Diagnosis } & \multicolumn{3}{c|}{ Histology Diagnosis } \\
\hline & & Benign & Malignant & $\begin{array}{c}\text { Inadequate/ } \\
\text { Normal Breast } \\
\text { Tissue }\end{array}$ \\
\hline Benign & 30 & 27 & 00 & 03 \\
\hline Malignant & 07 & 00 & 06 & 01 \\
\hline Unsatisfactory & 02 & 01 & 00 & 01 \\
\hline
\end{tabular}

Statistical analysis revealed Kappa score of 69\% (43.6 94.3) indicating a moderate degree of concordance between FNA cytology and histology. For the purpose of statistical analysis, unsatisfactory results have not been considered for analysis. The sensitivity of FNAC is $100 \%$ (95\% CI 51.6-100), specificity is $96.4 \%$ (95\% CI - 79.7 - 99.8\%), positive predictive value is $85.7 \%$ (95\% CI - $42-99.2 \%)$ and negative predictive value is $100 \%(0.07-57.9 \%)$ in our study. Likelihood ratio of FNAC for positive result is 28 (4.08-191.8 0).

\section{DISCUSSION}

Breast lump is one of the most common surgical problems in females. Virtually every woman with a breast lump, breast pain or discharge from nipple fears that she has breastcancer. Early diagnosis is the key to increase survival.
However social factors, religious factors, unawareness of fatality of the disease, false vanity and fear of infertility hinder early diagnosis and treatment. Cancer of the breast is the most common cancer in women worldwide and patients usually present with a palpable breast lump. Not only the malignant lesions pose a major public health problem, but benign lesions also contribute to the morbidity and they can masquerade as malignancy which can cause significant mental anguish to the patients. Breast cancer is the most common cancer in women all over India. Due to lack of awareness and almost non-existent breast screening practices, most of the patients present in advanced stages of disease.

The high incidence of breast malignancy, its relatively easy detection at an early stage, and effective treatment in the form of conservative surgery and chemotherapy had prompted a worldwide initiation of triple assessment i.e. clinical (Palpation), radiologic (Ultrasonography or mammography), and cytological (FNAC) assessment. The age of the patients in our study ranged from 7-88 year with mean age of 36 year. Maximum incidence of breast lesions was seen in the age group of 21-30 year. Maximum number of benign breast disease were seen in the age group of 21-30 year and maximum number of malignant breast diseases were seen in the age group of 41-50 year. Our findings were comparable with other studies.9,10,11,12 As per statistics from Breast Cancer India (BCI), the average age of developing a breast cancer has undergone a significant shift over last few decades. An increasing number of patients are in the 25 to 40 year of age. In our study $65.6 \%$ cases were seen in the age group of 31-50 year. In our study, left breast was more commonly involved in females which is comparable with the study done by Supriya et al ${ }^{13}$. The most common presenting symptom in females in our study was lump breast (96.5\%) while $3.4 \%$ had diffuse swelling. Our findings are comparable with Homesh et al, ${ }^{12}$ who showed that $88.5 \%$ of their patients presented with breast lump. Most common location of lump in in our study was upper half of breasts (51.8\%) while $32.4 \%$ cases presented with lump in lower half of breasts. Our finding are comparable with other studies. ${ }^{11,14,15}$ Upper outer quadrant was the most commonly involved quadrant in females. 50\% females had lump in the upper outer quadrant in the study done by Saha et al.(2016) ${ }^{11}$ and El-Ghorori et al.(2004)14 in their study reported that $58 \%$ presented with lumps in upper quadrants. Hussain (2005), ${ }^{16}$ in his series had $58 \%$ of female patients in whom upper outer quadrant of breast was involved. The size of lumps varied from $0.2 \mathrm{~cm}$ to $10 \mathrm{~cm}$ in our study. Out of 7 breast lumps with size more than $5 \mathrm{~cm}, 57.1 \%$ were malignant and $42.8 \%$ were benign. In our study, $98.6 \%$ of benign lesions were up to $5 \mathrm{~cm}$ in size while $90.6 \%$ of malignant lesions were more than $2 \mathrm{~cm}$ in size. These findings suggest that lumps of larger size had more chances of being malignant than of smaller size lumps. The goal of the breast cancer screening is to reduce deaths due to breast cancer by detecting breast cancer early, and reduce the incidence of advanced disease. Breast cancer has to reach a certain size to be detected. Breast cancers found by clinical breast examination or by a woman herself have a median size of 2 to $2.5 \mathrm{~cm} .{ }^{17}$ Such cancers are more likely to be in advanced stage and are more likely to have already spread to the axillary lymph nodes and are more likely to be lethal. Breast cancers found with high-quality, two-view screening 
mammography are relatively small, with median size 1.0 to $1.5 \mathrm{~cm} .{ }^{17}$ Approximately $10 \%$ of invasive cancers $1 \mathrm{~cm}$ in size or smaller have spread to lymph nodes at the time of detection, compared to close to $35 \%$ of those $2 \mathrm{~cm}$ in size and $60 \%$ of those $4 \mathrm{~cm}$ or larger in size.18 The measured size represented by the largest dimension of a mammary carcinoma is one of the most significant prognostic variables. Numerous studies have shown that survival decreases with increasing tumour size and that there is a coincidental rise in the frequency of axillary lymph node metastases 19,20,21 In our study, out of 16 malignant cases, 5 presented with palpable axillary lymph nodes, 2 with retracted nipple, 1 with ulcerated lesion and 2 cases with peau d' orange appearance of the overlying skin. Axillary lymph nodes are usually the first anatomic site to be involved by metastases in patients with breast carcinoma. Ioachim et al. ${ }^{22}$ opined that axillary lymph nodes are palpable in $50 \%$ to $60 \%$ of patients with clinically detected primary breast carcinomas and the frequency of palpable lymph nodes is much lower in patients in whom the primary breast neoplasms are not detected by physical examination and usually identified by mammography. Whether or not cancer has spread to lymph nodes is the most important prognostic factor for carcinoma breast. Carcinoma breast that has spread to lymph nodes has a higher risk of recurrence and a less favourable prognosis than breast cancer that has not spread to the lymph nodes. The number of metastatic lymph nodes is also important. The more positive lymph nodes there are, the higher the risk that carcinoma breast will recur. On evaluation of breast lumps using FNAC, in our study major group of disease in our study were benign breast lesions (74.24\%). Among the benign diagnosis, 34.84\% cases were Fibroadenoma, 20.45\% were Fibroadenomatosis, $16.66 \%$ were fibrocystic change. In our study fibroadenoma is the most common benign lesion which correlates with the other studies.23,24,25 The incidence of fibrocystic change in our study is 16.66 and its incidence is very variable in different series. ${ }^{24,25,26}$ It is important to distinguish benign breast lesions from breast carcinoma because the majority of benign lesions are not associated with an increased risk for subsequent breast cancer, hence unnecessary surgical procedures can be avoided. It is also important to distinguish benign lesions from in-situ and invasive breast cancer and to assess a patient's risk of developing carcinoma breast, so that the most appropriate treatment modality for each case can be established. In our study, $12.12 \%$ cases were reported as carcinoma on FNAC, which is comparable with other studies. ${ }^{24,27,28,29}$ In our study, there were $13.63 \%$ cases of benign inflammatory lesions and majority of these were acute mastitis and breast abscess. Incidence of inflammatory lesions also vary in different series. 30 The other lesions diagnosed by FNAC were fat necrosis and granulomatous mastitis.

In our study the absolute sensitivity of FNAC is $100 \%$ (95\% CI 51.6 - 100), specificity is $96.4 \%$ (95\% CI - 79.7 $99.8 \%)$. The positive predictive value is $85.7 \%$ (95\% CI - 42 $99.2 \%$ ) and negative predictive value is $100 \%$ ( $0.07-57.9 \%)$. Likelihood ratio of FNAC for positive result is 28. Literature review reveals that there is a variation in sensitivity, specificity, positive predictive value and negative predictive value. ${ }^{31,11,12}$ This difference in sensitivity and specificity of FNAC may be because of difference in patient population, operator dependant FNAC procedure and type of lesion.

\section{CONCLUSION}

In our study, maximum number of cases were of benign lesions (74.2\%) followed by $12.4 \%$ inflammatory lesions (12.4\%) and malignant lesions (10.06\%). $10.06 \%$ cases of carcinoma. Among the benign diagnosis, Fibroadenoma (20.06\%) was the most common. Absolute sensitivity of FNAC is $100 \%$ (95\% CI 51.6-100), specificity is $96.4 \%$ (95 $\% \mathrm{CI}-79.7-99.8 \%$ ). The positive predictive value is $85.7 \%$ (95\% CI - 42-99.2\%) and negative predictive value is $100 \%$ (0.07-57.9\%). Likelihood ratio of FNAC for positive result is 28. That means fine needle aspiration can fairly distinguish inflammatory, benign and malignant lesions of breast. Therefore, fine needle aspiration can be used for mass screening of population for carcinoma breast.

\section{REFERENCES}

[1] Ferlay J, Soerjomataram I, Ervik M, et al. GLOBOCAN 2012 v1.0, Cancer Incidence and Mortality Worldwide: IARC Cancer Base No. 11, 2013 [Internet]. Lyon, France: International Agency for Research on Cancer. http://globocan.iarc.fr

[2] Bray F, Ren JS, Masuyer E, et al. Global estimates of cancer prevalence for 27 sites in the adult population in 2008. Int J Cancer 2013;132(5):1133-45.

[3] National Cancer Registry Program: Consolidated report of the Hospital Based Cancer Registries, 20122014, an assessment of the burden and care of cancer patients. Indian Council of Medical Research, New Delhi, 2016.

[4] Anderson WF, Schairer C, Chen BE, et al. Epidemiology of inflammatory breast cancer (IBC). Breast Disease 2005-2006;22:9-23.

[5] Porter P. "Westernizing" women's risks? Breast cancer in lower-income countries. $\mathrm{N}$ Engl J Med 2008;358(3):213-6.

[6] Green M, Raina V. Epidemiology, screening and diagnosis of breast cancer in the Asia-Pacific region: current perspectives and important considerations. Asia Pac J Clin Oncol 2008;4:S5-S13.

[7] Aggarwal V, Agarwal G, Lal P, et al. Feasibility study of safe breast conservation in large and locally advanced cancers with use of radiopaque markers to mark preneoadjuvant chemotherapy tumor margins. World J Surg 2008;32(12):2562-9.

[8] Jan M, Mattoo JA, Salroo NA, et al. Triple assessment in the diagnosis of breast cancer in Kashmir. Indian Journal of Surgery 2010;72(2):97-103.

[9] Hebbar AK, Iyanna H. Prospective study of fine needle aspiration cytology of clinically palpable breast lump with histopathological correlation. Int J Res Med Sci 2013;1(3):257-62.

[10] Garg S, Mohan H, Bal A, et al. A comparative analysis of core needle biopsy and fine-needle aspiration cytology in the evaluation of palpable and mammographically detected suspicious breast lesions. Diagn Cytopathol 2007;35(11):681-9.

[11] Saha A, Mukhopadhyay M, Das C, et al. FNAC versus core needle biopsy: a comparative study in evaluation of palpable breast lump. J Clin Diagn Res 2016;10(2):EC05-8. 
[12] Homesh NA, Issa MA, El-Sofiani HA. The diagnostic accuracy of fine needle biopsy aspiration cytology versus core needle biopsy for palpable breast lump(s). Saudi Med J 2005;26(1):42-6.

[13] Supriya S, Nirmala C, Raghupathi LSA. Fine needle aspiration cytology verses core needle biopsy in breast lesions - a comparative study. Int J Cur Res Rev 2015;7(9).

[14] El-Ghorori RMH, Ewais MK. Fine needle aspiration cytology vs core needle biopsy in diagnosis of benign breast lesions. AAMJ 2004;2(2).

[15] Kim A, Lee J, Choi JS, et al. Fine needle aspiration cytology of the breast, experience at an outpatient breast clinic. Acta Cytol 2000;44(3):361-7.

[16] Hussain MT. Comparison of fine needle aspiration cytology with excision biopsy of breast lump. JCPSP 2005;15(4):211-4.

[17] Guth U, Huang DJ, Huber M, et al. Tumor size and detection in breast cancer: self-examination and clinical breast examination are at their limit. Cancer Detect Prev 2008;32(3):224-8.

[18] Ries LAG, Eisner MP. Cancer of the female breast. In: Ries LAG, Young JL, Keel GE, et al. eds. seer survival monograph: cancer survival among adults: US SEER Program, 1988--2001, patient and tumor characteristics Bethesda: National Cancer Institute, SEER Program, NIH Pub. No. 07-6215, 2007:101-10.

[19] Mitra SK, Rajesh R, Mishra RK, et al. Comparative evaluation of FNAC, core needle biopsy and excisional biopsy in subtyping of breast lesions. Tropical Pathol \& Microbiol 2016;2(1):9-15.

[20] Ballo MS, Sneige N. Can core needle biopsy replace fine-needle aspiration cytology in the diagnosis of palpable breast carcinoma. Cancer 1996;78(4):773-7.

[21] Shastri RK. Fine needle aspiration cytology verses trucut biopsy in preoperative planning of surgical treatment of breast lumps. IOSR-JDMS 2016;15(7):7480.
[22] Ioachim HL, Medeiros JL. Ioachim's Lymph Node Pathology. Chapter - 88. In: Ioachim HL, Medeiros JL, eds. Metastatic Breast Carcinoma. $4^{\text {th }}$ edn. Lippincott Williams \& Wilkins 2009: p. 6-14.

[23] Kuijper A, Mommers EC, Van der Wall E, et al. Histopathology of fibroadenoma of the breast. Am J Clin Pathol 2001;115(5):736-42.

[24] Rahman MZ, Islam S. Fine needle aspiration cytology of palpable breast lump: a study of 1778 cases. Surgery 2013;S12(01). doi:10.4172/2161-1076.S12001.

[25] Kumar R. A clinicopathologic study of breast lumps in Bhairahwa, Nepal. Asian Pac J Cancer Prev 2010;11(4):855-8.

[26] Mayun AA, Pindiga UH, Babayo UD. Pattern of histopathological diagnosis of breast lesions in Gombe, Nigeria. Niger J Med 2008;17(2):159-62.

[27] Rupom TU, Choudhury T, Banu SG. Study of fine needle aspiration cytology of breast lump: correlation of cytologically malignant cases with their histological findings. BSMMU J 2011;4(2):60-4.

[28] Pradhan M, Dhakal HP. Study of breast lump of 2246 cases by fine needle aspiration. J Nepal Med Assoc 2008;47(172):205-9.

[29] Chaurasiya AK, Patel AK, Khatun T, et al. Study of breast lesions in a tertiary care centre: a retrospective study. Med Phoenix 2017;2(1):48-51.

[30] Sumeera FSK, Kumar KS, Singh R, et al. Diagnostic accuracy of FNAC in evaluation of breast lumps. JMSCR 2016;4(02):9275-9.

[31] Bukhari MH, Arshad M, Jamal S, et al. Use of fineneedle aspiration in the evaluation of breast lumps. Article ID 689521, Pathology Research International 2011;2011: p. 10. 